\title{
Emoción en acción. El caso de \#RosarioSangra en Twitter (Rosario, Argentina, 2016)
}

\section{Emotion in action. The case of \#RosarioSangra on Twitter}

(Rosario, Argentina, 2016)

\author{
Irene Lis Gindin, CONICET (Consejo Nacional de Investigaciones Científicas y Técnicas) \\ Universidad Nacional de Rosario (Argentina) \\ iregindin@gmail.com|http://orcid.org/0000-0002-3080-0207
}

Sebastián Ramiro Castro Rojas, Universidad Nacional de Rosario (Argentina) scastrorojas@gmail.com|http://orcid.org/0000-0003-1122-8660

Natalia Coiutti, Universidad Nacional de Rosario (Argentina)

coiuttin@gmail.com|http://orcid.org/0000-0001-7918-8787

Ana Laura Cardoso, Universidad Tecnológica Nacional Regional Rosario (Argentina) cardosoalaura@gmail.com|http://orcid.org/0000-0002-2867-3317

José Francisco Rostagno, Universidad Tecnológica Nacional Regional Rosario (Argentina) joserostagno@hotmail.com|http://orcid.org/0000-0001-8346-0261

\begin{abstract}
Resumen
En este artículo, a partir del análisis de un caso particular, buscamos comprender el modo en que algunas temáticas propias de los intereses ciudadanos logran traspasar las redes digitales para convertirse, mediante la acción colectiva y la identificación ciudadana, en marchas o movilizaciones sociales. El caso objeto de estudio, \#RosarioSangra -tal el nombre con el que se conoció el fenómeno-, tuvo lugar en Rosario (Argentina) durante el año 2016 y surgió a partir de una serie de hechos delictivos que pusieron a la temática de la seguridad y la justicia en el centro de la escena pública. Tomando a la red social Twitter nos proponemos indagar acerca de las formas en que los internautas expresaron su malestar e indignación sobre los acontecimientos que sucedían en la ciudad, tanto a partir del análisis de la recurrencia de palabras y hashtags como de un acercamiento de tipo semiótico a una serie de imágenes que circularon por la red social bajo estudio para convocar a las distintas movilizaciones que aquí
\end{abstract}

Forma de citar:

Gindin, I., Castro Rojas, S., Coiutti,N., Cardoso, A. y Rostagno, J. (2019). Emoción en acción. El caso de \#RosarioSangra en Twitter (Rosario, Argentina, 2016). Ámbitos. Revista Internacional de Comunicación 43(1), 48-69. doi: 10.12795/Ambitos.2019.i43.03. 
estudiamos. En este trabajo tensamos métodos tradicionales cuantitativos y cualitativos con la minería de datos, recuperando los tweets publicados entre agosto y noviembre de 2016. Los resultados de esta investigación nos conducen a ubicar a Twitter como un laboratorio de opiniones (de Ugarte, 2012) que, sin capacidad de organización, funcionó como catalizador de malestar y como modo de visibilizar la indignación.

\begin{abstract}
In this article, from the analysis of a particular case, we seek to understand the way in which some themes of citizen interests manage to transfer digital networks to become, through collective action and citizen identification, in social mobilizations. The case under study, \#RosarioSangra -such the name with which the phenomenological became known-, took place in Rosario (Argentina) during 2016 and emerged from a series of criminal acts that placed the subject of security and justice at the center of the public stage. Taking the social network Twitter we propose to inquire about the ways in which Internet users expressed their discomfort and indignation about the events that happened in the city, both from the analysis of the recurrence of words and hashtags as well as a semiotic approach to a series of images that circulated through the social network to summon the different mobilizations that we study here. In this paper we tighten traditional quantitative and qualitative methods with data mining, recovering tweets posted between August and November 2016. Based on certain theoretical hypotheses we define Twitter as a laboratory of opinions (de Ugarte, 2012) that, without organizational capacity, worked as a catalyst for discomfort and as a way to making visible indignation.
\end{abstract}

Palabras clave: Twitter, participación, redes sociales, RosarioSangra.

Keywords: Twitter, participation, social networks, RosarioSangra.

\title{
1. INTRODUCCIÓN1
}

El artículo que presentamos pretende una indagación en dos niveles, de lo micro a lo macro. Por un lado, y en un nivel micro, tomaremos un caso en particular para preguntarnos acerca de las formas en que Twitter fue usado por los internautas para expresar su malestar e indignación en relación a un conjunto de hechos de inseguridad ocurridos en la ciudad de Rosario, Argentina. Por otro lado y a partir de aquí, proyectamos este caso en vistas a comprender el modo en que ciertos discursos sobre lo público que son visibilizados a partir de su publicación en las redes sociales en internet (en adelante, RSI) adquieren, por fuera de ellas, visibilidad en el espacio público tradicional o visibilidad mediática. Es decir, cómo algunas temáticas propias de los intereses 
ciudadanos logran traspasar las redes digitales para convertirse, mediante la acción colectiva y la identificación ciudadana, en marchas o movilizaciones sociales.

El caso que analizamos fue conocido como \#RosarioSangra y podemos situarlo a partir de una serie de hechos delictivos que tuvieron lugar en la ciudad de Rosario (Argentina) durante el año 2016. Fabricio Zulatto, Nahuel Ciarroca, Héctor Villalba -entre otros- despertaron la movilización ciudadana luego de ser protagonistas de una situación de inseguridad de la que resultaron víctimas fatales. Los hechos, ocurridos en agosto de 2016 en zonas del macrocentro, fueron acontecimientos que impulsaron a la ciudadanía, fundamentalmente rosarina, a solicitar justicia por lo ocurrido y mayor protección para circular por la ciudad. Si bien estos tres hechos no explican por sí solos el porqué de la movilización ciudadana, creemos que actuaron como catalizadores del malestar social acumulado en los meses y años anteriores. De hecho, si recurrimos a las cifras del Ministerio Público de la Acusación (2017)², en el año 2016 la cantidad de homicidios que tuvieron lugar en la ciudad descendió en relación a años anteriores. El malestar y la indignación -algunas de las pasiones puestas en juego-, primero, fueron tomando cuerpo generando discusiones e intercambios en las plataformas digitales, mediante el intercambio de comentarios, posteos y tweets para, progresivamente, ganar espacio en la prensa -tanto local como nacional- y luego materializarse en la calle. Esta visibilidad en el espacio público tradicional aconteció en varias oportunidades entre los meses de agosto y noviembre de 2016. Para este trabajo se identificaron más de diez movilizaciones y se decidió focalizar la mirada en tres de ellas: 25 de agosto, 8 de septiembre y 10 de noviembre. Estas tres cumplían con los criterios establecidos a priori: concentraciones/marchas gestadas por grupos locales en la blogósfera digital y en función, no de un hecho delictivo concreto, sino por el reclamo de mayor seguridad y justicia.

Creemos necesario resaltar que, si bien las movilizaciones ciudadanas, bajo la forma de concentraciones, cortes de calles, presencia en tribunales, etc., tienen una importante tradición a nivel nacional, el caso bajo estudio presenta la particularidad de registrar cierto malestar que aparece, primero, en la esfera digital, para luego visibilizarse en la esfera pública tradicional y ganar el espacio físico.

En este sentido nos preguntamos acerca del modo en que estos discursos sobre lo público aparecen en la red social Twitter, qué particularidades tienen y cuál es el comportamiento de los hashtags que nuclearon las conversaciones desplegadas allí. Proponemos, asimismo, el análisis de ciertas imágenes que circularon en la red social y que sirvieron como modo de convocar a las tres movilizaciones antes mencionadas. 
Este trabajo se inserta en un conjunto de saberes previos que, a modo de estado del arte, han aportado para pensar nuestro objeto. Podemos afirmar que la proliferación de fenómenos sociales como la denominada primavera árabe, el 15M español, el movimiento de Occupy Wall Street y, más cercano geográfico y temporalmente, las protestas de los estudiantes chilenos, y las diversas manifestaciones generadas alrededor del \#yosoy132 en México o del \#NiUnaMenos en varias ciudades latinoamericanas, ha dado lugar a un conjunto considerable de estudios. Rescatamos aquellos que abordan la relación entre protestas sociales y RSI —entre otros, véase Anduiza, Cristancho y Sabucedo (2014), Breuer (2012), Bryne (2011), Burch y León (2014), Castells (2012), Eltantawi y Wiest (2011), Ghonim (2012), Harvey, Teles, y Sader (2012), Kiss y Rosa-García (2011) y Sandoval-Almazan y Gil-Garcia (2014).

Este estudio también supone, a largo plazo, repensar la categoría de esfera pública, inicialmente propuesta por Habermas (1989), a partir de recuperar no sólo su tesis sino las principales lecturas a que fue sometido —véase, Dahlgren (2008, 2013, 2018), Downey (2014), Fraser (1992), Keane (1997), Mehl (1997), Negt (2007) y Thompson (1996, 1998, 2011).

Como nos recuerda Thompson (2011), tanto en los originarios planteos de Arendt (2008) como en los de Habermas (1999) ya estaba presente el reconocimiento del lugar esencial otorgado al lenguaje y al discurso como elementos constitutivos de la esfera pública y en este intersticio sumamos los trabajos de Raimondo Anselmino, Reviglio y Diviani (2016) y Rusconi (2006).

Para el análisis propuesto se utilizará un cruce entre metodologías cualitativas y cuantitativas -métodos de análisis computacionales como la minería de datos-. Esto supone una hibridación entre un acercamiento computarizado y otro de tipo artesanal, y siguiendo a Fernández (2017), de nivel micro; es decir "se enfocan productos en sus procesos: objetos industriales y artesanales, textos artísticos o mediáticos".

Dividiremos nuestro artículo en tres partes. En primer lugar, realizaremos una revisión de los presupuestos teóricos sobre los que se sustenta nuestra investigación y explicaremos las decisiones metodológicas, tanto aquellas que corresponden al criterio de selección y análisis del corpus como a las propias de la ingeniería en sistemas que nos han permitido obtener los datos que serán la materia prima de este artículo. En segundo lugar, presentaremos los resultados obtenidos junto a una descripción de cada uno de ellos. Por último, nos centraremos en el análisis de dichos resultados, señalando los aportes de esta investigación y delineando posibles líneas futuras de trabajo. 


\section{REVISIÓN TEÓRICA Y PLANTEAMIENTO DEL PROBLEMA}

Propio de un campo caracterizado por su multidisciplinaridad, como es el de las Ciencias de la Comunicación, el objeto de estudio de este trabajo atraviesa distintos dominios que sólo pueden ser comprendidos a partir de una articulación de variadas perspectivas teóricas. De aquí que en nuestro recorrido conceptual se incorporen autores propios de la semiótica, la filosofía, la lingüística, la semiología, etc.

El punto de partida de este artículo supone pensar, como propone Dahlgren (2018), en el aspecto afectivo de la participación política en línea entendiendo que lo que lleva a la participación es algo más que lo que sucede en la mente de un sujeto, es la experiencia social, dado que "el afecto implica el lado colectivo de la emocionalidad" (p. 33). Además, esta participación se ancla en lo político (Mouffe, 2007) e involucra siempre algún tipo de lucha o confrontación, interviniendo en las relaciones de poder. De aquí se derivan disputas identitarias en las que se imbrican aspectos emocionales y racionales: es dentro de esta tensión en la que se inserta el sentido de la participación. Además, entendemos, junto a Dahlgren (2018), que los medios sociales -como Twitter- se han transformado en recursos cívicos tanto para el compromiso como para la participación; aunque no pasamos por alto que, tal como lo plantea Amossy (2018), "los intercambios en la Red son acusados por algunos de dar curso libre a una violencia descontrolada y peligrosa, en tanto otros celebran en ella un instrumento de participación ciudadana y de democratización" (p. 164). Las RSI se han convertido en un espacio de manifestación de valores, de construcción de esfera pública. Sin embargo, ésta no es ya entendida al modo de Habermas (1989) "como dominio de nuestra vida social en el que algo así como la opinión pública puede conformarse" (p. 1), atada al consenso, la racionalidad y que, por tanto, oblitera el conflicto. Thompson (2011) apunta a pensar a la esfera pública como un "espacio complejo de flujos de información donde 'ser público' significa 'ser visible' en este espacio, ser capaz de ser visto y oído por otros" (p. 33). A partir de aquí recuperamos la noción de esfera pública virtual elaborada por Vázquez (2013) no sólo "como un canal alternativo a los medios masivos, sino como un espacio de disputa política" (p. 147). Estas categorías teóricas puestas en tensión posibilitan problematizar el caso \#RosarioSangra y cómo el malestar social, materializado en discursos, aparece en la esfera pública virtual. Por ello, en sintonía con Thompson (2011), asumimos que el conflicto es inevitable y estructurante de esta esfera.

La singularidad del fenómeno que estudiamos se entiende a la luz del viraje de la emoción a la acción que desarrolla Castells (2012): "el big bang de un movimiento social empieza en la transformación de la emoción en acción” (p. 30). Esta emoción transformada en acción supuso 
el paso de lo que Thompson (2011) denomina la visibilidad propia de los medios electrónicos a la visibilidad situada de la co-presencia, pasando, claro está, por la visibilidad mediática. Esto es así en tanto es en las redes donde los ciudadanos deliberan, comentan noticias y hechos de violencia y generan, mediante sus interacciones y posteos, un clima emocional de identificación con los otros que lleva, asimismo, un fuerte componente identitario.

Además, si hay algo que atraviesa el fenómeno que analizamos, eso es algo del orden de la indignación. Nos detendremos, en páginas siguientes, en el paso de la deliberación a la movilización que desarrolla de Ugarte (2012). Recuperamos los planteos del autor porque nos permiten pensar, por fuera de ciertas perplejidades, qué hay de nuevo en los funcionamientos de las redes sociales; en tanto, si pensamos que las redes permiten la vinculación de una/s persona/s con otra/s, en realidad la sociedad siempre ha funcionado de forma reticular. El autor establece una tipología para pensar los modos de organizar una red y que sirven para comprender los nuevos fenómenos sociales y políticos. Al respecto, identifica tres: uno, en el que ha primado el poder centralizado; de aquí el paso al poder descentralizado y, por último, la emergencia del poder distribuido. Nos detendremos en el tercero que es el que da cuenta de las redes distribuidas, en las que no existe filtro alguno, es una red de iguales, un sistema pluriárquico en el que se registra conexión de par a par entre distintos nodos de la red. Es la blogósfera el primer medio de comunicación distribuido, "un entorno informativo en el que se reproducen los presupuestos, las condiciones y los resultados del mundo pluriárquico" (p. 33). Este funcionamiento a nivel macro está dado, entre otras cosas, por la capacidad de propagabilidad que presentan las tecnologías digitales y, en especial, las RSI. La propagabilidad, de acuerdo a Jenkins, Ford y Green (2015) da cuenta del "potencial -tanto técnico como cultural- del público a la hora de compartir contenido con sus propios propósitos" (p. 25); propagabilidad que permite la multiplicación del contenido a niveles nunca antes visto.

En términos metodológicos y como hemos dicho previamente, el objeto de estudio de este trabajo tensiona métodos tradicionales cuantitativos y cualitativos con la minería de datos.

En primer lugar, el equipo de investigación delimitó el marco temporal del trabajo a los meses de agosto a noviembre de 2016. Para conformar el corpus se implementaron dos estrategias de recolección de tweets distintas en base a las características particulares del caso \#RosarioSangra en cuanto a su extensión en el tiempo.

Por un lado se recuperó un conjunto de tweets en tiempo real a través de un pequeño programa en lenguaje R que se conecta a la plataforma Twitter mediante su Interfaz de Programación de 
Aplicaciones (API). Por otro lado, se adicionó un nuevo conjunto de tweets recolectados con un programa realizado en lenguaje Python que utiliza la búsqueda histórica de Twitter.

Luego de un trabajo de pre procesamiento y limpieza de datos, el corpus de tweets para el análisis quedó conformado por 18462 tweets. Cabe destacar que ambas estrategias de obtención de tweets trabajan sobre una muestra limitada ${ }^{3}$ a la que permite acceder la plataforma, siendo esto un condicionante para el posterior análisis.

En segundo lugar, se confeccionó una nube de palabras en R. Para esto se procesó el texto de cada uno de los tweets removiendo las denominadas stopwords, las cuales son palabras sin significado tales como artículos, pronombres, preposiciones, etc. Acto seguido, se generó un vector de frecuencia de palabras, el cual indica la cantidad de veces que aparece cada palabra en el corpus de los tweets. Esto nos permitió detectar marcas discursivas, emociones, particularidades que se reiteraban en los tweets objetos de nuestro análisis.

En tercer lugar, se utilizó el método de análisis interpretativo de los tweets publicados para convocar a las concentraciones de agosto, septiembre y noviembre. Para ello, además de los textos, se seleccionaron 3 tweets cuyas imágenes convocaban a las marchas, dado que fueron esas las imágenes que mayor circulación tuvieron en la red social objeto de análisis. A partir de los conceptos propuestos por Barthes (1964), Peirce (1987) y Verón (1996), damos cuenta de las distintas significaciones que se desprenden de estas imágenes. En este sentido, es un acercamiento al corpus de tipo interpretativo que recupera, asimismo, todo el conjunto de discursos circulantes a modo de condiciones de producción (Verón, 1998) de nuestro objeto de estudio.

\section{RESULTADOS}

En el presente parágrafo, damos cuenta de los resultados principales que hemos obtenido mediante la recolección de los datos.

Del procesamiento con el software RStudio se presentan los resultados en la Tabla $N^{0} 1$ : 
Tabla 1. Ocurrencias de palabras en la totalidad de los tweets recolectados

\begin{tabular}{|r|l|r|}
\hline \multicolumn{1}{|c|}{ Palabra } & \multicolumn{2}{c|}{ Ocurrencias } \\
\hline $\mathbf{1}$ & marcha & 786 \\
\hline $\mathbf{2}$ & seguridad & 639 \\
\hline $\mathbf{3}$ & rosario & 632 \\
\hline $\mathbf{4}$ & justicia & 443 \\
\hline $\mathbf{5}$ & inseguridad & 442 \\
\hline $\mathbf{6}$ & basta & 327 \\
\hline $\mathbf{7}$ & gente & 265 \\
\hline $\mathbf{8}$ & ciudad & 253 \\
\hline $\mathbf{9}$ & tribunales & 211 \\
\hline $\mathbf{1 0}$ & hoy & 206 \\
\hline $\mathbf{1 1}$ & fe & 187 \\
\hline $\mathbf{1 2}$ & socialismo & 181 \\
\hline $\mathbf{1 3}$ & gobierno & 155 \\
\hline $\mathbf{1 4}$ & santa & 150 \\
\hline $\mathbf{1 5}$ & rosarinos & 144 \\
\hline $\mathbf{1 6}$ & hace & 141 \\
\hline $\mathbf{1 7}$ & ahora & 137 \\
\hline $\mathbf{1 8}$ & anos & 137 \\
\hline $\mathbf{1 9}$ & pueblo & 137 \\
\hline $\mathbf{2 0}$ & multitudinaria & 130 \\
\hline
\end{tabular}

Fuente: elaboración propia

Lo que muestra esta tabla es la cantidad de veces que una determinada palabra aparece en la totalidad del corpus, eliminando -tal como dijimos previamente- las stopwords y, además, aquellas palabras que remitían a usuarios de la red o a hashtags. La cantidad de palabras (limpias) distintas es de 6049 y la cantidad de palabras (limpias) totales asciende a 34052.

Al ver los datos recolectados con el word frequency aparecen ciertas palabras que se visibilizan como generadoras de comunión con las emociones y que produjeron empatía e identificación: 


\section{Figura 1. Nube de palabras}

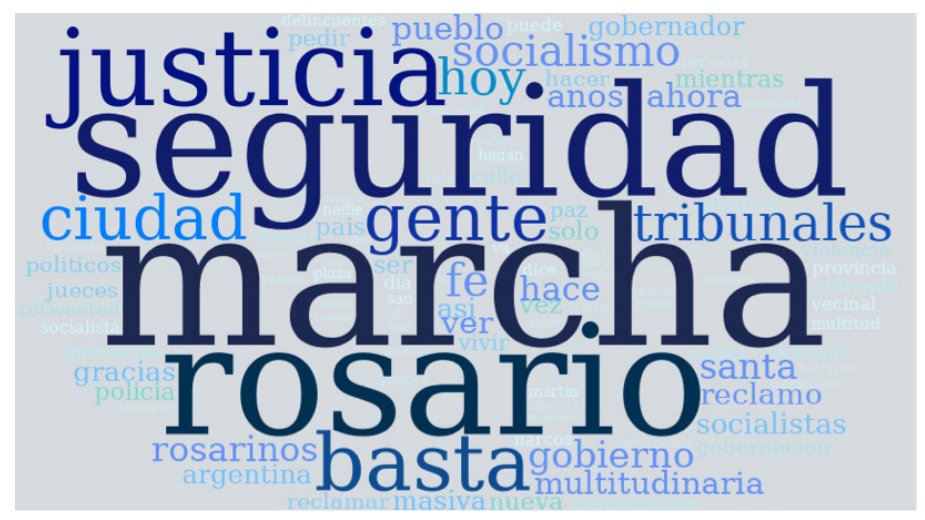

Fuente: elaboración propia

Además de la clara primacía de la palabra marcha, es el caso de las palabras seguridad, rosario, justicia, inseguridad, basta, las que muestran mayor recurrencia de aparición.

Sin embargo, gran parte de la importancia del microbbloging que estamos analizando radica en la utilización de hashtags. Podemos verlos en la Tabla №2.

Aclaremos en principio que lo que muestra la Tabla $\mathrm{N}^{0} 1$ es la cantidad de veces que determinadas palabras fueron publicadas en el período estudiado en el universo total de tweets; a diferencia de la segunda en la que se encuentran discriminados aquellos sintagmas o conjuntos de palabras que se utilizaron como hashtags. Si consideramos que cada palabra de los 140 caracteres de un tweet es una unidad textual encontramos que las palabras y los hashtags que circularon con motivo de las movilizaciones son los que están en los primeros lugares como aquellos más mencionados o usados por los que escribieron los tweets. La importancia de que una palabra sea utilizada como hashtag es que la entendemos como un elemento semiótico relevante (Menna, 2012) "que establece relaciones sintagmáticas con el resto de los constituyentes del tuit" (Mancera Rueda \& Pano, 2015, p. 63). Además, estas etiquetas terminan por tomar autonomía discursiva que condensan la ideología y los valores políticos del movimiento (Menna, 2012). Siguiendo a Zappavigna (2011, citado en Mancera Rueda \& Helfrich, 2014), los hashtag funcionan como etiquetas tematizadoras que generan un ambiente de afiliación, ampliando no sólo los significados de los tweets sino también permitiendo el desarrollo de la conversación con otros usuarios para adicionar así presencia en la web. En el plano discursivo, los hashtags se han utilizado en algunos casos para hacer juicios de valor con semántica negativa y para contextualizar el tiempo y el espacio en donde se realizaban las marchas. 
Tabla 2. Top 20 de hashtags más utilizados

\begin{tabular}{|c|c|c|}
\hline & Hashtag & Ocurrencias \\
\hline 1 & \#rosariosangra & 6477 \\
\hline 2 & \#rosariomarcha & 407 \\
\hline 3 & \#rosario & 241 \\
\hline 4 & \#narcosycomplices & 199 \\
\hline 5 & \#seguridad & 142 \\
\hline 6 & \#justicia & 119 \\
\hline 7 & \#ahora & 116 \\
\hline 8 & \#santafesangra & 107 \\
\hline 9 & \#juevesintratable & 101 \\
\hline 10 & \#inseguridad & 88 \\
\hline 11 & \#persecucionajueces & 81 \\
\hline 12 & \#narcosocialismo & 67 \\
\hline 13 & \#rosariociudadliberada & 64 \\
\hline 14 & \#hoyrosariosangra & 45 \\
\hline 15 & \#objetivocfk & 38 \\
\hline 16 & \#rosarioestadepie & 36 \\
\hline 17 & \#prejuzgamiento & 31 \\
\hline 18 & \#juiciopoliticoamarijuan & 30 \\
\hline 19 & \#argentina & 28 \\
\hline 20 & \#lanochedeml & 28 \\
\hline
\end{tabular}

Fuente: elaboración propia

Si analizamos los hashtags más usados vemos que \#RosarioSangra condensó el sentimiento generalizado de los internautas que se hicieron presentes en la blogósfera para expresar su malestar social. Este sintagma funcionó como aglutinador de las opiniones y articuló las emociones y la acción individual y colectiva que allí circuló. Además, si atendemos a los tres primeros hashtags de la Tabla $\mathrm{N}^{0} 2$ podemos advertir que, en todos los casos, es la palabra rosario (acompañada por sangra, en el primero caso; por marcha, en el segundo; y sola, en el tercero) la que impera ${ }^{4}$. Rosario aparece en estos ejemplos no sólo situando el tweet en un aquí sino, también, ubicando a la ciudad como un actor que realiza determinadas acciones: sangrar y marchar. 
La cronología de las marchas y la evolución del fenómeno, nos aportan también algunas claves para pensar en su paulatina decadencia, cuestión que podemos observar en la Figura 2:

Figura 2. Cantidad de tweets a través del tiempo

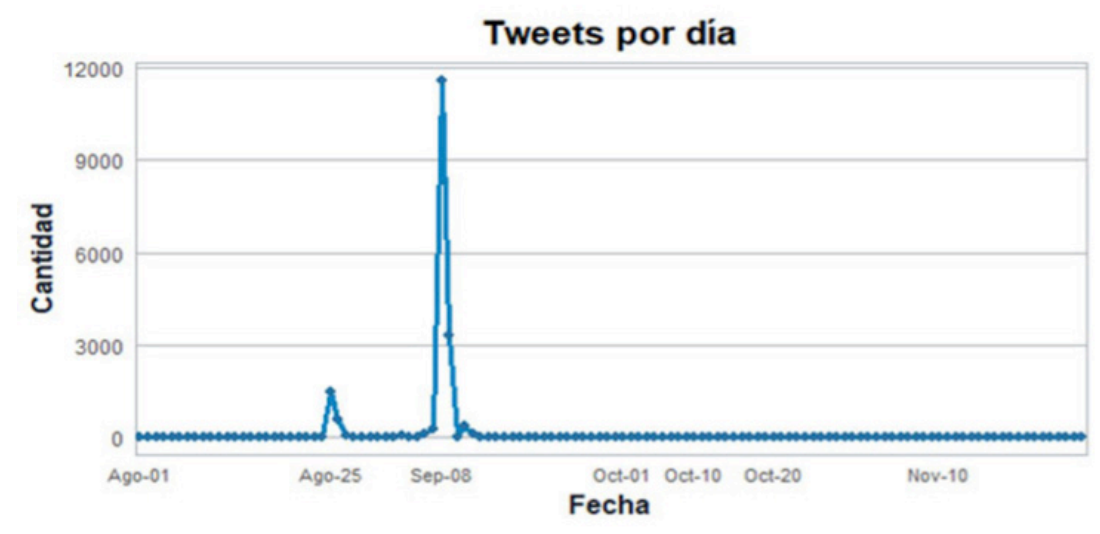

Fuente: elaboración propia

A partir de la discriminación de las tres marchas, es menester recalcar que, de acuerdo a los datos recabados, durante el día de la primera, el 25 de agosto, se contabilizaron una totalidad de 1490 tweets $^{5}$. En cuanto a los hashtags ${ }^{6}$, las siguientes palabras fueron Trending Topic (TT) a nivel local: rosariosangra, lacra, multitud, marcha, tribunales, rosariomarcha, bastadeinseguridad, basta, nomasinseguridad, nadiemenos, rosariopidejusticia. Por su parte, a nivel nacional, la página www.trendinalia.com ubica a \#RosarioSangra como TT en el puesto número $8^{7}$.

En cuanto a la segunda marcha, la que acontece el 8 de septiembre, los hashtags que llegan a convertirse en TT a nivel local son menores, registrándose sólo uno a las 22:14 y que es movilización. Algo similar sucede a nivel nacional, dado que el hashtag \#RosarioSangra se sitúa en el número 25 el día 9 de septiembre. De los datos recabados por el equipo de investigación, el 8 de septiembre se registraron 11607 tweets $^{8}$. Por último, en la tercera convocatoria, la del 10 de noviembre, no se registran TT ni locales ni nacionales. De los datos recabados por el equipo de investigación, ese día se registró sólo un tweet ${ }^{9}$.

Tal como adelantamos, nos interesa analizar, desde un plano semiótico, ciertas imágenes que fueron las que mayor circulación tuvieron en la red social y que se utilizaron como modo de convocatoria. Nos referimos a las siguientes figuras. 
Figura 3. Imagen que circuló en Twitter para convocar a la primera movilización

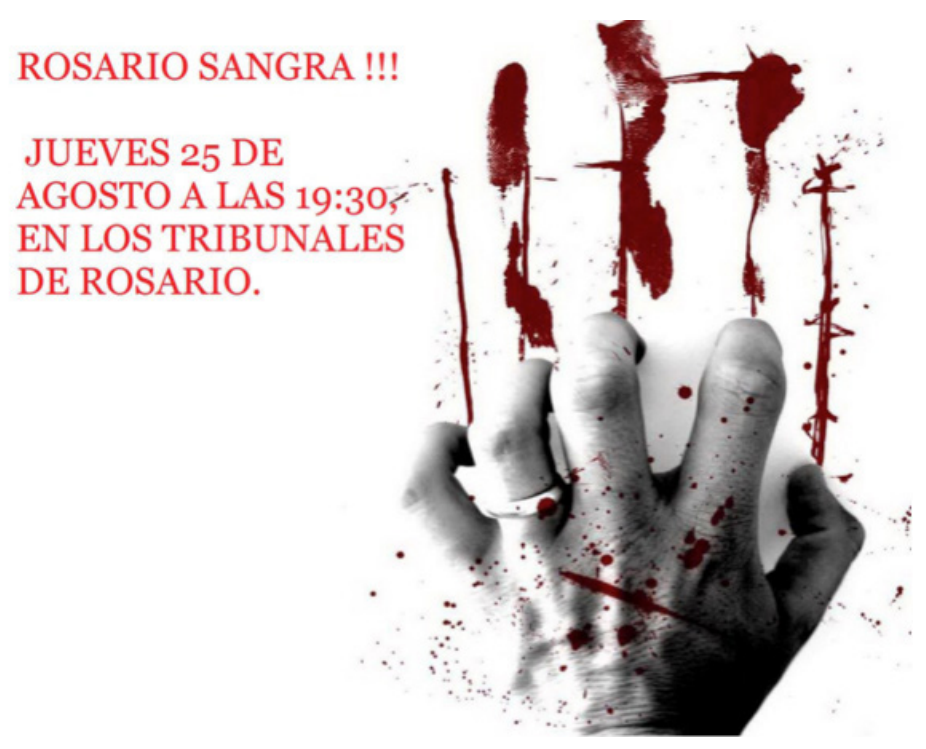

Fuente:https://twitter.com/RosarioSufre/status/767072492536094721

Figura 4. Imagen para convocar a la segunda movilización

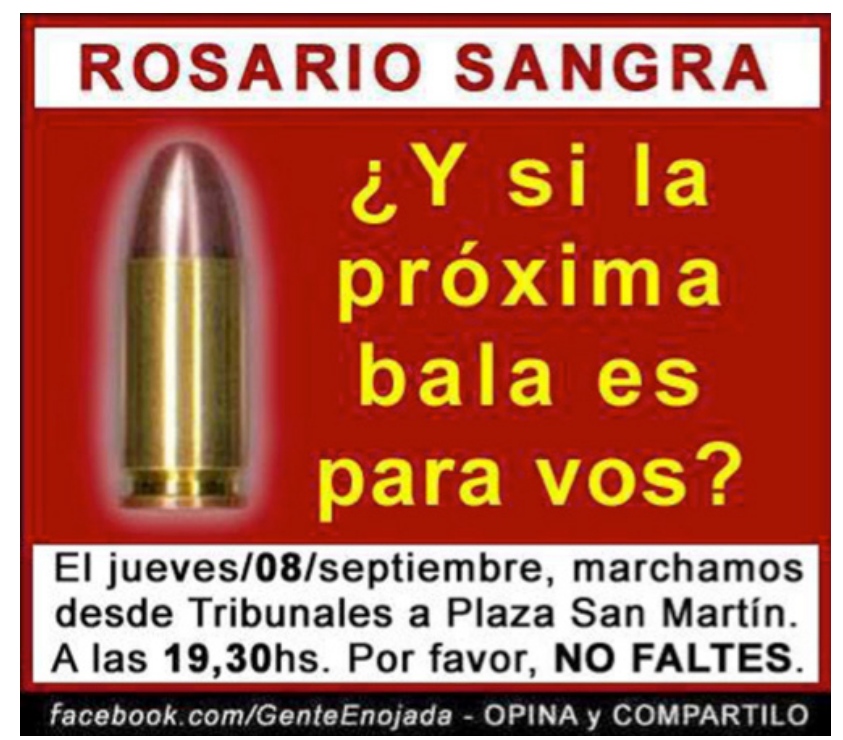

Fuente: twitter.com 
Figura 5. Imagen para convocar a la tercera movilización

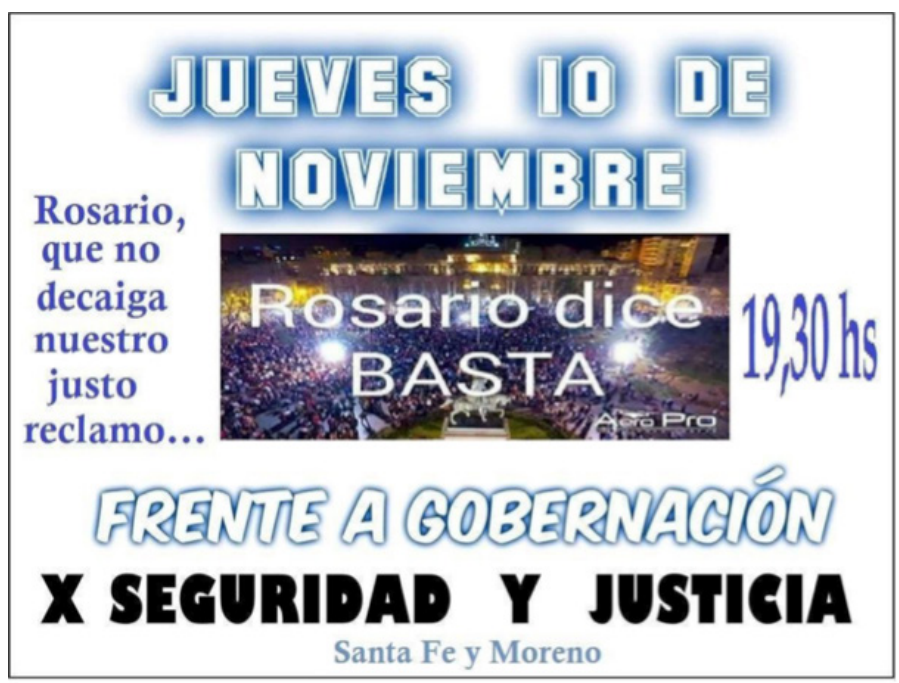

Fuente:https://twitter.com/MumiYadanza/status/796354236556656640

Si nos remitimos a la Figura 3 observamos una de las principales imágenes que circuló en Twitter para convocar a la primera marcha. Si pudiésemos despejar la imagen de sus connotaciones y describirla de forma pura, tal como lo manifiesta Barthes (1964), podríamos decir que la misma cuenta con una mano con manchas rojas sobre ella y su alrededor. Siguiendo al autor, entendemos que ésta sería una mirada literal y a un nivel superficial de la percepción ya que toda imagen remite a significados más amplios, culturales y globales que posee el lector. Algunas características sobresalientes en el plano connotativo se vinculan con la idea de la mano -en forma de garracomo muestra del dolor y del sentimiento desgarrador de los familiares de las víctimas de estos asesinatos; aludiendo a la ira y al enojo. Tomando como referencia a Peirce (1987), podríamos decir entonces que las manchas rojas funcionan en la composición como íconos a través de los cuales se establece una relación de semejanza con respecto al objeto: en este caso nos remiten a gotas y rastros de sangre.

Asimismo, la imagen también brinda una "sustancia lingüística" (Barthes, 1964) cuyo soporte es la leyenda "Jueves 25 de agosto a las 19:30 en los Tribunales de Rosario". Podemos detectar aquí un mensaje lingüístico subyacente a través del color y la tipografía elegidos. El rojo de las letras, sumado al contexto en el que se encuentra la imagen, nos remiten al color de la sangre y por lo tanto, refieren al dolor, al sufrimiento y a la profunda congoja de los familiares de las víctimas. En cuanto a la tipografía seleccionada, el uso de las letras mayúsculas y la tipografía estilo bold 
determinarían una necesidad de llamado de atención, similar a un grito en una comunicación verbal. Estos sentimientos de dolor y padecimiento también pueden encontrarse reflejados en las manchas rojas que se encuentran dibujadas sobre el fondo blanco (el cual también podría actuar como una pared). Si tomamos los conceptos de Verón (1996), podríamos decir entonces que la composición de esta imagen funciona como un tipo de fotografía categorial ya que se emplean diferentes objetos con el fin de aludir a nociones que requieren un mínimo de convencionalidad para que el mensaje pueda ser comprendido, acercándose más a un tipo de discurso artístico.

En cuanto a la Figura 4 vemos que, para la confección de la pieza, se eligió una combinación de palabras e imagen y que, si bien hay menos contenido figurativo que escrito, la contundencia de la imagen equilibra ambos elementos. En este caso, se escogió el color rojo de fondo, remitiendo una vez más a la sangre derramada por las víctimas. Asimismo, el anclaje de la frase superior nos recuerda al slogan de la marcha anterior: Rosario Sangra. La contundencia de la imagen de la bala demuestra que no se incorporó un dibujo del objeto, sino una fotografía del mismo. Esta fotografía, retocada en sus bordes con un esfumado blanco, impacta por la similitud con una bala verídica. Aquí, gracias al mensaje escrito, hay poco espacio para la connotación. La interpelación al lector, a través de un acto de habla interrogativo, junto al elemento fotografiado que reza " ¿Y si la próxima bala es para vos?" funcionan como una estrategia de exhortación al receptor, a través de la cual se infiere que, de no asistir a la marcha y de no actuar al respecto, las situaciones de violencia continuarán y por lo tanto, el lector del mensaje podría ser la próxima víctima. Luego, en la parte inferior, se observa un tipo de mensaje informativo con el día, el lugar, la hora de la marcha y finalmente la leyenda "Por favor, no faltes", con fondo blanco y un tono más ameno. Finalmente, al pie de la composición, en fondo negro, se observan dos tipos de acto de habla: el informativo y el imperativo. En el primero, se brinda la información de una página de Facebook y en el segundo, a modo de orden, se incita a los ciudadanos a dar su opinión y a compartir el flyer.

La última imagen a analizar es la Figura 5 que convoca a la tercera marcha y en la misma se apela nuevamente a las palabras y a las imágenes. Aquí, la proporción de ilustración y vocablos es marcadamente desigual ya que se colocaron mayoritariamente frases verbales, incluso superponiéndose a la imagen. En este caso, la fotografía elegida para la composición fue tomada por un dron en una de las manifestaciones anteriores. En la misma, se observa una gran cantidad de ciudadanos en la plaza San Martín de la ciudad de Rosario, frente a la Sede de Gobernación, lugar donde se había citado a los rosarinos en las anteriores manifestaciones y al cual se convoca en esta última. Observamos, también, que sobre la fotografía se encuentra 
la leyenda "Rosario dice BASTA" escrita en una fuente de palo seco, color blanco y la palabra "BASTA" escrita con letras mayúsculas, representando el cansancio y la necesidad de respuesta de las autoridades ante los lamentables acontecimientos. Así es como, utilizando variados estilos y pesos tipográficos, se intenta interpelar al lector para lograr su asistencia a la marcha. A su vez, a través del acto de habla informativo, aclara el día, lugar y hora de la manifestación. Además, sobre el lateral izquierdo, se lee la frase "Rosario, que no decaiga nuestro justo reclamo..." exhortando una vez más a los ciudadanos a continuar ocupando el espacio público y, tal como lo venían haciendo en anteriores oportunidades, haciendo foco en la necesidad de seguir ganando la calle.

\section{DISCUSION Y CONCLUSIONES}

En este artículo nos propusimos analizar un caso particular de movilización ciudadana, \#RosarioSangra, con el fin de comprender el modo en que ciertos discursos sobre lo público aparecieron en la red social Twitter, qué particularidades adquirieron y cuál fue el comportamiento de los hashtags que nuclearon las conversaciones desplegadas allí. Asimismo, analizamos tres imágenes que fueron las que mayor circulación tuvieron en la red social como modo de convocatoria a las movilizaciones estudiadas.

Por un lado y vinculado con los antecedentes de este trabajo, dimos cuenta de un tipo de participación online que sólo puede ser entendida al ser puesta en relación con el concepto de lo político (Mouffe, 2007) como intervención en las relaciones de poder. Para Dahlgren (2018), esta participación se relaciona con lo emocional y, por ende, con el afecto que, según entiende, conlleva siempre compromiso. Dice el autor: "comprometerse con algo no implica sólo atención cognitiva y tal vez una postura normativa, sino también una intervención subjetiva" (p. 32). Esta intervención subjetiva pudo ser observada en las recurrencias de palabras que, en su mayoría, ponían el acento en aspectos desfavorables del contexto. Pero, además y de modo fundamental, esta intervención se produce en la esfera pública -hoy, digital, virtual- que, tal como lo entiende Thompson (2011), generara una simultaneidad desespacializada.

Una pregunta que se desprende de los resultados, siguiendo a de Ugarte (2012) es: ¿es posible pensar el caso \#RosarioSangra a partir de la idea de poder distribuido? Afirmamos anteriormente que, en las redes distribuidas, un individuo cualquiera puede dar a conocer su malestar sin pasar necesariamente por un filtro; sin pasar, por ejemplo, por el gran filtro que otrora suponían los medios de comunicación. Si atendemos a estas primeras características descriptas, la categoría del autor se aplica perfectamente al caso de estudio porque, tal como hemos dicho previamente, el fenómeno \#RosarioSangra cobró visibilidad, primero, en las RSI y fue después de ello, que los medios de comunicación -en especial, la prensa local- se hicieron eco ${ }^{10}$. 
Entendemos que las formas de uso y apropiación de las redes por parte de los internautas en el contexto de \#RosarioSangra pueden ser comprendidas como una acción -individual, colectivaque posibilita la propagabilidad de los mensajes. Un cibernauta que comparte y re-twittea los contenidos de las marchas posee mentalidad colaborativa o propagable; es decir, una mentalidad que "se basa en crear textos mediáticos que el público diverso (con propósitos dispares) pueda poner en circulación" (Jenkins, et.al., 2015, p. 28). Lograr visibilidad es el gran desafío de estos movimientos, pasar de ese primer momento de laboratorio social a otro de ocupación de las calles; salir de la blogósfera para poblar los medios de comunicación; convertirse, en fin, en una ciberturba, es decir, "la culminación en la movilización en la calle de un proceso de discusión social llevado a cabo por medios electrónicos de comunicación y publicación personales en el que se rompe la división entre ciberactivistas y movilizados" (de Ugarte, 2012, p. 56). Esto es, exactamente, lo que hemos observado en nuestro caso de estudio.

Otra cuestión de interés que se desprende de los resultados obtenidos en esta investigación radica en la ausencia de un líder (o varios) que actúe nucleando y uniendo a los distintos nodos de la red, característica distintiva de las redes distribuidas. Creemos, sin embargo, que en este sentido \#RosarioSangra se presenta de una manera un tanto híbrida porque, si bien es posible hallar algunas personas que cobraron mayor visibilidad -por ejemplo, personas que fueron invitadas a participar de programas televisivos o notas radiales; que se encargaron de la organización de los eventos en Facebook y de darle mayor visibilidad al tema- esto no necesariamente se tradujo en una estructura jerárquica que propone, mientras la gran movilización dispone. En el caso de Facebook y tal como explicamos en un artículo anterior (Reviglio et.al., 2017), las organizaciones de los eventos, la difusión, la presencia en los medios locales y la organización de las movilizaciones recayeron tanto en algunas organizaciones de la sociedad civil como en ciertos particulares que no registraban vínculo previo. Nos referimos a: "Mesa de Compromiso Ciudadano", "Familiares de Víctimas y Vecinos Autoconvocados" y "ONG Red Antimafia Rosario". Sin embargo, ninguna de estas organizaciones registra cuentas de Twitter y la participación vía este microblogging de los particulares, es significativamente marginal. Lo que se produce allí es ese laboratorio de opiniones al que se refiere de Ugarte, como catalizador del malestar e, incluso, como modo de visibilizar esa indignación; más no como lugar en el que se organizan las manifestaciones. Esto es así, en parte, por las propias posibilidades de las plataformas. Es decir, sabemos que Twitter es, antes que nada, una red de microblogging que, durante el período de estudio, permitía la publicación de tweets con un máximo de 140 caracteres. A diferencia de Facebook, en Twitter no existen grupos o fan pages que nucleen más fácilmente 
a los cibernautas y esto genera un tipo de circulación de contenidos distinto. Sin ir más lejos, Van Dijck (2016) retomando un estudio previo, sostiene que, en el 2010 , sólo el $22 \%$ de los usuarios tenía relaciones recíprocas de seguimiento, mientras que el $68 \%$ no era seguido por las personas a las que siguen. Además, en términos comparativos, el uso de Twitter es menor que el de Facebook ${ }^{11}$. Tanto este menor uso como el hecho de la no reciprocidad en los contactos, se vuelve visible en la cantidad de favoritos o retweets que tienen los mensajes que tomamos como corpus: sólo aquellas cuentas más populares (por ejemplo, las cuentas de diarios o las cuentas de políticos que participaron del movimiento \#RosarioSangra) dan lugar a una circulación más fluida; mientras que la mayoría de los tweets registran muy poco nivel de engagement.

Quisiéramos destacar dos últimas cuestiones en relación a posibles líneas de trabajo que se deducen de esta investigación. Por un lado, el equipo de investigación continúa trabajando para lograr una articulación entre las distintas dimensiones que se imbrican en el fenómeno \#RosarioSangra, en la que la comparación entre Facebook y Twitter podría otorgarnos mayores conocimientos respectos de los distintos usos, potencialidades y límites de dichas plataformas. En segundo lugar y en un nivel macro, consideramos que a medida que los ciudadanos se apropian y experimentan sus formas de interacción y participación en la esfera digital se abren nuevos interrogantes de estudio. A las plataformas como Facebook y Twitter, hoy se le suman Instagram y WhatsApp. Por ello, comienzan a emerger nuevas línea de trabajo para comprender los usos de las redes de mensajería instantánea; tal el caso de WhatsApp en las elecciones presidenciales de Brasil en 2018 y las elecciones regionales de Andalucía en España. Estos hechos son indicios que permiten seguir pensando las transformaciones sociales, las maneras de participar y de convocar tanto a las manifestaciones como a los potenciales electores. Las tecnologías digitales, las redes, en fin, las formas de socialidad on-line continúan siendo un laboratorio social híbrido que debe ser estudiado desde las distintas disciplinas.

Para cerrar estas reflexiones, volvemos a Castells (2012). El sentimiento de malestar que produjeron las oleadas de delitos resultó en que una importante parte de la ciudadanía rosarina manifestara la necesidad de compartir, de poner en común esta serie de emociones generando empatía, proximidad, cercanía. Pero, tal como lo aborda el autor, era necesario superar el miedo para movilizar, miedo que se transforma en indignación, al sentir identificación con algo indeseable que le pasa a otra persona:

Esta identificación se consigue mejor compartiendo sentimientos en una forma de compañerismo que se crea en el proceso de comunicación. La segunda condición para que las experiencias individuales se conecten y formen un movimiento es, por tanto, 
la existencia de un proceso de comunicación que propague los acontecimientos y las emociones ligadas a las mismas. Cuanto más rápido e interactivo sea el proceso de comunicación, más probable es que se forme un proceso de acción colectiva, arraigado en la indignación, impulsado por el entusiasmo y motivado por la esperanza (Castells, 2012, p. 32).

\section{NOTAS}

${ }^{1}$ Este artículo surge en el seno de un proyecto de investigación que vincula a la Universidad Nacional de Rosario con la Universidad Tecnológica Nacional (Rosario, Argentina). El proyecto se titula "Nuevas visibilidades en la cultura digital: esfera pública contemporánea y redes sociales en internet" (Secretaría de Investigación y Posgrado, Universidad Nacional de Rosario, Argentina. Código del proyecto: 1POL253. Unidad ejecutora: Centro de Investigaciones en Mediatizaciones).

2 Ver https://mpa.santafe.gov.ar/mediafiles/nw5a8d8dbe36ff6 31 Informe\%20de\%20 Homicidios\%202016\%20-\%20Provincia\%20de\%20Santa\%20Fe.pdf (última consulta: 10 de diciembre de 2018).

${ }^{3}$ Sobre dicha limitación, ver: https://developer.twitter.com/en/docs/basics/rate-limiting (última consulta: 11 de diciembre de 2018).

${ }^{4}$ No hay que despreciar, sin embargo, la enorme diferencia que se registra entre el primer hashtag (6477 ocurrencias) y el segundo (407 ocurrencias).

${ }^{5}$ Registramos, asimismo, la cantidad de tweets del día anterior y posterior: 10 tweets el día 24-08 y 565 el día $26-08$.

${ }^{6}$ Ver https://twitter.com/TrendsRosario (última consulta: 11 de diciembre de 2018).

7 Ver http://www.trendinalia.com/twitter-trending-topics/argentina/argentina-160826.html (última consulta: 11 de diciembre de 2018).

${ }^{8}$ Registramos, asimismo, la cantidad de tweets del día anterior y posterior: 279 tweets el día $07-$ 08 y 3290 el día 09-09.

${ }^{9}$ Registramos, asimismo, la cantidad de tweets del día anterior y posterior: 6 tweets el día 09-11 y 1 tweet el día 11-11. 
${ }^{10}$ Para un análisis completo acerca del fenómeno en la prensa local, sugerimos la lectura de Raimondo Anselmino, N.; Reviglio, M. C. y Echecopar, C. (2018).

${ }^{11}$ La Encuesta Nacional de Consumos Culturales realizada por el Sistema de Información Cultural de la Argentina ubica el uso de Facebook en un 60.6\% (primer lugar) mientras que Twitter queda reservado a un tercer lugar con un $10.6 \%$. Datos disponibles en: https://encuestadeconsumo. sinca.gob.ar/practicas digitales (última consulta: 11 de diciembre de 2018).

\section{REFERENCIAS}

Amossy, R., (2018). Apología de la polémica, Buenos Aires, Argentina: Prometeo.

Anduiza, E., Cristancho, C. y Sabucedo, J.M. (2014). Mobilization through online social networks: The political protest of the indignados in Spain. Information, Communication \& Society, 17 (6), pp. 750-764.

Arendt, H., (2008). La condición humana, Barcelona, España: Paidós.

Barthes, R., (1964). Elementos de semiología, París, Francia: Éditions du Seuil.

Breuer, A. (2012). The Role of Social Media in Mobilizing Political Protest. Evidence from the Tunisian Revolution. Discussion paper, 10. Recuperado de https://www.die-gdi.de/uploads/ media/DP 10.2012.pdf

Bryne, J., (2011). The Ocuppy Handbook, New York, USA: Back Bay Bokss

Burch, S. y León, O. (2014). Social Movements, Democratic Participation and ICTs. En Breuer, A. y Welp, Y. (Eds.), Digital Technologies for Democratic Governance in Latin America (pp.127-145), Nueva York, USA: Routledge.

Dahlgren, P. (2008). El espacio público y los medios. ¿Una nueva era?. En Veyrat-Masson, I. y Dayan, D. (Comps). Espacios públicos en imágenes (pp.245-268). Barcelona, España: Gedisa.

Dahlgren, P., (2013). The political web. Media, participation and alternative democracy, Basingstoke, Reino Unido: Palgrave Macmillan.

Dahlgren, P. (2018). La participación en línea en la esfera pública. Las ambigüedades del afecto, InMediaciones de la Comunicación, Vol. 18 (N¹), pp. 25-47. Recuperado de https://revistas. ort.edu.uy/inmediaciones-de-la-comunicacion/article/view/2824

Castells, M., (2012). Redes de indignación y esperanza: Los movimientos sociales en la era de Internet, Barcelona, España: Alianza Editorial.

de Ugarte, D., (2012). El poder de las redes, Buenos Aires, Argentina: Aurelia Rivera Libros.

Downey, J. (2014). Flux and the public sphere, Media Culture Society, 36 (3), pp. 367-379. 
Eltantawi, N. y Wiest, J. (2011) Social Media in the Egyptian Revolution: Reconsidering Resource Mobilization Theory, International Journal of Communication, Vol. 5, pp. 1207-1224. Recuperado de https://ijoc.org/index.php/ijoc/article/view/1242

Jenkins, H., Ford, S., y Green, J., (2015). Cultura Transmedia. La Creación de contenido y valor en una cultura en red, Barcelona, España: Gedisa.

Fernández, J.L. (2017). Las mediatizaciones y su materialidad: revisiones. En Busso, M. y Camusso, M. (Eds.), Mediatizaciones en tensión: el atravesamiento de lo público (pp.1029). Rosario, Argentina: UNR Editora.

Fraser, N. (1992). Rethinking the public sphere: A contribution to the critique of actually existing democracy. En Calohun, C. (Ed.). Habermas and the public sphere (pp.109-142). Cambridge, Reino Unido: MIT Press

Ghonim, W., (2012). Revolution 2.0. The power of the people is greater than the people in power. A memoir, Boston, USA: Houghton Mifflin Harcourt.

Habermas, J. (1989). The Public Sphere. En Seidman, S. (ed.). Jüngen Habermas on Society and Politics. A reader. Boston: Beacon Press. Traducción de Daniel M. Giménez.

Habermas, J., (1999). Historia y crítica de la opinión pública La transformación estructural de la vida pública, Barcelona, España: Gili.

Harvey, D., Teles, E. y Sader, E., (2012) Occupy: movimentos de proteso que tomaram as ruas, São Paulo, Brasil: Bointempo.

Keane, J. (1997). Transformaciones estructurales de la esfera pública, Estudios Sociológicos, 43, pp. 47-77. Recuperado de https://estudiossociologicos.colmex.mx/index.php/es/article/ view/873/0

Kiss, J. y Rosa-García, A. (2011). Why do Facebook and Twitter facilitate revolutions more than TV and radio?, Munich Personal RePEc Archive, № 33496. Recuperado de_https://mpra. ub.uni-muenchen.de/33496/1/MPRA paper 33496.pdf

Mehl, D. (1997). La 'vida pública privada'. En Veyrat-Masson, I. y Dayan, D. (Comps), Espacios públicos en imágenes (pp.90-114). Barcelona, España: Gedisa.

Negt, O., (2007). L'espace public oppositionnel, Paris, Francia: Payot

Mancera Rueda, A. y Pano Alamán, A. (2015). Valores sintáctico - discursivos de las etiquetas en Twitter, Círculo de Lingüística Aplicada a la Comunicación, 64, pp. 58-83. Recuperado de https://revistas.ucm.es/index.php/CLAC/article/viewFile/51278/47584 
Mancera Rueda, A. y Helfrich, U. (2014). La crisis en 140 caracteres: el discurso propagandístico en la red social Twitter, Revista Cultura, Lenguaje y Representación, XII, pp. 59-86. Recuperado de www.raco.cat/index.php/CLR/article/viewFile/278146/365992

Menna, L. (2012). Nuevas formas de significación en Red: el uso de las etiquetas en el movimiento \#15M, Estudios de Lingüística del Español, 34. Recuperado de elies.rediris.es/elies34/ Tesina_L-Menna.pdf

Ministerio de Cultura de la Argentina (2018). Buenos Aires, Argentina: Sistema Nacional de Información Cultural de la Argentina. Recuperado de https://www.sinca.gob.ar/

Mouffe, Ch., (2007). En torno a lo político, Buenos Aires, Argentina: FCE.

Peirce, Ch., (1987). Obra lógica semiótica, Madrid, España: Taurus Comunicación.

Raimondo Anselmino, N., Reviglio, M.C. y Diviani, R. (2016). Esfera pública y redes sociales en Internet: ¿qué es lo nuevo en Facebook?, Revista Mediterránea de Comunicación, 7 (1), pp. 211-229. Recuperado de https://www.mediterranea-comunicacion.org/article/ view/2016-v7-n1-esfera-publica-y-redes-sociales-en-internet-que-es-lo-nuevo-en-facebook

Raimondo Anselmino, N.; Reviglio, M. C. y Echecopar, C. (2018). \#RosarioSangra en la prensa: Análisis de la puesta en discurso de movilizaciones ciudadanas, Revista Chilena de Semiótica, 8, pp. 25-47. Recuperado de https://revistachilenasemiotica.cl/ files/2000001396a8046b79e/Revista\%20Chilena\%20de\%20Semiotica\%208_FINAL-6.pdf

Reviglio, C., Raimondo Anselmino, N. y Gindin, I. (2017). Mediatización, visibilidades y circulación de discursos sobre lo público-político en torno al caso \#RosarioSangra. Notas para la delimitación de un objeto de estudio. En Busso, M. y Camusso, M. (Eds.), Mediatizaciones en tensión: el atravesamiento de lo público (pp. 107-126). Rosario, Argentina: Universidad Nacional de Rosario.

Rusconi, C. (2006). Espacio público mediático, comunidad y ciudadanía. En Grillo, M., Rizzo, A. y Berti, S. (Comps.), Con los medios de por medios (pp. 205-224). Río Cuarto, Argentina: UNRC.

Sandoval-Almazan. R. y Gil-García, R. (2014). Towards cyberactivism 2.0? Understanding the use of social media and other information technologies for political activism and social movements, Government Information Quarterly, 31(3).

Thompson, J. (1996). La teoría de la esfera pública, Voces y Cultura, 10.

Thompson, J. (1998). La transformación de la visibilidad. En Los media y la modernidad. Una teoría de los medios de comunicación (pp.161-198). Barcelona, España: Paidós. 
Thompson, J. (2011). Los límites cambiantes de la vida pública y la privada, Revista Comunicación y Sociedad, $N^{\circ} 15$, enero-junio 2011, pp. 11-42. Recuperado de http://www.scielo.org.mx/ pdf/comso/n15/n15a2.pdf

Van Dijck, J., (2016) La cultura de la conectividad. Una historia crítica de las redes sociales, Buenos Aires, Argentina: Siglo XXI Editores.

Vázquez, M. (2013). Primeras aproximaciones a la esfera pública virtual. En Fernández, M. (et. al.); Giordano, C (Dir.), Lo público en el umbral. Los espacios y los tiempos, los territorios y los medios (pp. 138-163). La Plata, Argentina: Universidad Nacional de La Plata.

Verón, E. (1996). De la imagen semiológica a las discursividades. El tiempo de una fotografía. En Veyrat-Masson, I. y Dayan, D. (Comps.), Espacios públicos en imagen (pp. 47-70). Barcelona, España: Gedisa.

Verón. E., (1998). La semiosis social. Fragmentos de una teoría de la discursividad. Barcelona, España: Gedisa. 